\title{
Analysis of volatile components in beer containing Cordyceps militaris extract by electronic nose and GC-MS
}

\author{
Jikang Jiang ${ }^{\mathrm{a}}$, Jiyuan Tian ${ }^{\mathrm{a}}$, Wenxiang $\mathrm{Li}^{\mathrm{b}, *}$, Ge Yu${ }^{\mathrm{a}}$ \\ ${ }^{a}$ Qingdao Agricultural University, Qingdao 266109 China \\ b Qingdao Agricultural University, Key Laboratory of Modern Agricultural Quality and Safety Engineering \\ of Qingdao, Shandong Provincial Laboratory of Applied Mycology, Qingdao 266109 China
}

*Corresponding author, e-mail: xiang7332@126.com

Received 15 Aug 2019

Accepted 25 May 2020

\begin{abstract}
In the present study, the volatile flavor compounds in beer containing Cordyceps militaris extract (CMB) were analyzed by solid-phase microextraction combined with gas chromatography-mass spectrometry (SPME/GC-MS) and electronic nose compared with normal beer (NB) as control. The results showed that, through principal component analysis (PCA) and loading analysis (LA), ester content of CMB was less than that of NB while alcohol content was higher. A total of 27 volatile compounds were identified by SPME/GC-MS from CMB and NB, classified into acids, alcohols, esters and terpenes.
\end{abstract}

KEYWORDS: Cordyceps militaris, beer, volatile flavor compounds, electronic nose, gas chromatography-mass spectrometry (GC-MS)

\section{INTRODUCTION}

Cordyceps militaris is an entomopathogenic fungus that invades insect larvae and pupae commonly known as caterpillar fungus. It belongs to families Clavicipitaceae and Ascomycotina, and has been used in oriental medicine for many years [1]. The bioactive compounds in $C$. militaris such as cordycepin, cordycepic acid, cordyceps polysaccharide and novel carotenoids have been reported to possess many effects including, but not limited to, antitumour, antioxidant, antiaging, immunomodulating and hypoglycaemic activities [2]. Nowadays, the artificial cultivation of $C$. militaris has basically achieved industrialization [3] and gradually developed for large scale and economic impact, especially the solid cultivation of $C$. militaris. However, the application of C. militaris products is still severely limited.

Beer, as the third largest consumption beverage in the world, has great consumption potential. In virtue of the production of $\mathrm{CMB}$, not only can it maintain beneficial components of $C$. militaris itself and enrich nutritional components of beer, but also improve the application of $C$. militaris, which responds to the emerging consumer demand for high quality, nutrition and safety. As we know, volatile compounds of beer play an important role for organoleptic evaluation. Beyond that, many studies have reported changes of aroma compounds in different health benefit beer, recently [4-7]. On the contrary, there have been no reports on the counterparts in CMB. Therefore, it is necessary to analyse volatile compounds in CMB.

The aim of our present work was to investigate the effect of extraction of C. militaris with soild fermentation on volatile components of beer by solid-phase microextraction combined with gas chromatography-mass spectrometry (SPME/GC-MS) and electronic nose.

\section{MATERIALS AND METHODS}

\section{Materials}

C. militaris products with solid fermentation were prepared by Qingdao Agricultural University laboratory (Shandong, China); two-row barely malt was purchased from a local market in Qingdao Country, Shandong, China; ALE514 dry yeast was from Australian Mauribrew company; and Cascade hop was from Yakima Chief-Hopunion LLC., USA.

\section{Preparation of extract from C. militaris (CME)}

CME was prepared as described by Yu et al [8]. Briefly, the solid fermentation product of $C$. militaris was dried in oven at $60^{\circ} \mathrm{C}$ and crushed through 


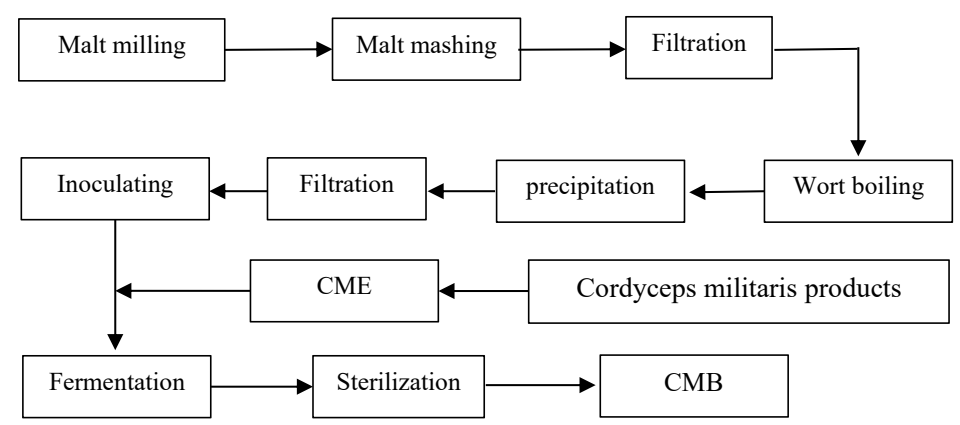

Fig. 1 Brewing technology process of CMB.

80 mesh sieve. Then samples was put in conical flask containing proper ethyl alcohol and placed in water bath (DK-S26 Shanghai Jing Hong Laboratory Instrument Co., Ltd., China) for $90 \mathrm{~min}$ at $45^{\circ} \mathrm{C}$. The supernatant, obtained by centrifugal filtration (3000 rpm, $10 \mathrm{~min}$ ) through a $0.2 \mu \mathrm{m}$ sterile Millipore filter to remove all cells was sterilized, then placed in the refrigerator after cooling.

\section{Brewing technology of CMB}

Brewing technology process of $\mathrm{CMB}$ is shown in Fig. 1. Broken malt was placed into mash tun followed by stirring at low temperature in case of agglomerate as heating leaching saccharification method and then placed into $50^{\circ} \mathrm{C}$ water bath for $30 \mathrm{~min}$. Next temperature was increased to $67^{\circ} \mathrm{C}$ for $1 \mathrm{~h}$. After that, temperature was increased to $78^{\circ} \mathrm{C}$ for $20 \mathrm{~min}$, then filter and obtain wort. $0.2 \mathrm{~g} / 1$ and $0.4 \mathrm{~g} / 1$ hops were used at the beginning and $30 \mathrm{~min}$ of the boiling process, respectively. By the end of boiling, $0.2 \mathrm{~g} / \mathrm{l}$ hops were added again. After that, the wort is quickly stirred in one direction to facilitate impurity precipitation in the wort. Put the boiling pot in aseptic table to cool down until below $30^{\circ} \mathrm{C}$ and filter with 6 layers of aseptic gauze. Wort is collected in a $1000 \mathrm{ml}$ triangle bottle with a oneway valve for fermentation. Then crude CME was obtained by cyclotron precipitation and filtering. After that, 5-10 times dried yeast was sprinkled in $30^{\circ} \mathrm{C}$ water and stirred gently for $15 \mathrm{~min}$ and let stand for $5 \mathrm{~min}$. The activated yeast was poured into the wort after cooling. Every liter of wort was inoculated with $0.5 \mathrm{~g}$ dry yeast. With that, CME accounting for $10 \%$ of wort volume was added to bub followed by inoculating yeast and the main fermentation was completed at $20^{\circ} \mathrm{C}$ for 7 days. Finally, the fermentation broth was then fermented in a pressurized brown bottle at $4^{\circ} \mathrm{C}$, pasteurized and centrifugated (4500 rpm, $\left.15 \mathrm{~min}, 4^{\circ} \mathrm{C}\right)$ to clarify beer.
NB was prepared as similar to CMB but without addition of ethanol extract of $C$. militaris.

\section{Electronic nose}

Electronic nose system (PEN3; AIRSENSE, Germany) was used as described by Zhu et al [9] with a slight modification.

Fifteen $\mathrm{ml}$ beer sample were placed in the glass sample bottle. Then the flavor composition of the sample filled the upper headspace and reached the equilibrium state. The headspace gas was absorbed with the electronic nose. Sample determination time interval lasted for $1 \mathrm{~s}$. Preparation time was $3 \mathrm{~s}$ and test time was $60 \mathrm{~s}$. After sampling performed, clean air filtered by activated carbon was pumped into the electronic nose, the sensor was cleaned and restored to its initial state with cleaning time of $100 \mathrm{~s}$. the volatile headspace gas was adsorbed through the sensor array, which made the conductivity change. The signal was acquired by the data acquisition system and stored in a computer. Each sample was measured 3 times in parallel at $25^{\circ} \mathrm{C}, 71 \pm 1 \%$ relative humidity. All analyses were performed in triplicate.

Electronic nose data was processed as $R(i)=$ $G / G_{0}, i=1,2, \ldots, 10$, where the ratio of signals $R$ was the ratio of the conductivity $G$ of the sample gas passing through the sensor to the conductivity $G_{0}$ of the standard gas filtered by activated carbon. $R(1)-R(10)$ were the number of 10 metal-oxide sensors.

\section{SPME/GC-MS}

Volatile compounds were analyzed by solidphase microextraction (SPME) and gas chromatography coupled to mass spectrometry (GC-MS 5975B/6890N; Agilent Technologies, Santa Clara, CA, USA) following the procedure previously reported by Sanchez et al [10] and Zhou et al [11] with a slight modification. Volatile compounds 
adsorbed on the SPME fiber (Qingdao Zhenzheng Industry and Trade Co., Ltd., China) were desorbed at $280^{\circ} \mathrm{C}$ for $60 \mathrm{~min}$ in the injector port of a GC interfaced with a mass detector (internal ionization source: $70 \mathrm{eV}$ ) with a scan range from $35-500 \mathrm{~m} / \mathrm{z}$. The ion source temperature was set at $230^{\circ} \mathrm{C}$. Elastic quartz capillary column used was DB-5MS $(30 \mathrm{~m} \times 0.32 \mathrm{~mm} \times 0.25 \mu \mathrm{m})$. The carrier gas used was high purity helium. The temperature of the GC started at $50^{\circ} \mathrm{C}$, raised to $150^{\circ} \mathrm{C}$ at a rate of $5^{\circ} \mathrm{C} / \mathrm{min}$ for $1 \mathrm{~min}$ and then raised to $230^{\circ} \mathrm{C}$ at $10^{\circ} \mathrm{C} / \mathrm{min}$ for $10 \mathrm{~min}$.

\section{Statistical analysis}

Principal component analysis is a multivariate statistical analysis technique. By identifying several principal component factors to represent many complex and difficult to discover variables in the original sample, the regularity and difference between samples were then evaluated according to the contribution rate of principal component factors in different samples. PCA highlights the difference in volatile compounds by signal strength [12].

Load is the correlation coefficient between the principal component and the corresponding original index variables. Overload analysis can be used to analyze the closeness between factors and individual variables. The contribution rate and correlation of different sensors to the first and second principal components can be judged [13].

Principal component analysis (PCA) and loading analysis (LA) was carried out by WinMuster 1.6.2.

\section{RESULTS}

\section{Electronic nose}

\section{Extraction of eigenvalue of sensor data}

As shown in Fig. 2, a curve represents a sensor, suggesting that changes of relative conductivity $G / G_{0}$ of volatile compounds in beer with time increased when they pass through sensor channel. The response intensity values of some sensors changed quickly at the early stage of detection and then tend to be stable after $56 \mathrm{~s}$. Meanwhile, the response intensity values of the other sensors did not change significantly. Therefore, the original data were analyzed by using the signal values of the curve which changed obviously between $56 \mathrm{~s}$ and $58 \mathrm{~s}$.

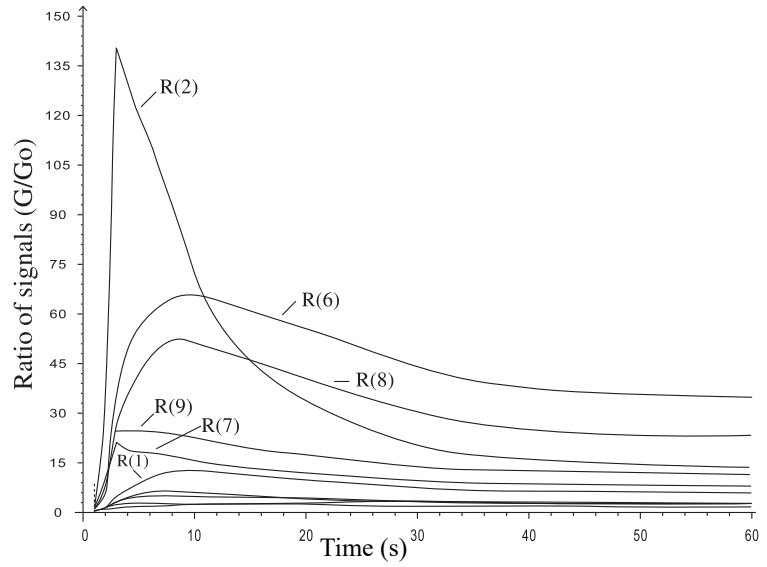

Fig. 2 Response graphs of electronic nose sensors to volatile compounds.

\section{Principal component analysis}

Principal component analysis (PCA) is a commonly used unsupervised learning method, widely used in data decomposition and visualization. It aims at mapping high dimensional variables in a low dimensional space. When the model is calculated, a straight line is first found to minimize the sum of the residual squares of all samples from the line, and the sum of the vector squares projected in the direction of this number axis is the largest, then the direction of the straight line also reflects the maximum difference between the samples, resulting in the first principal component (PC1); on this basis, the second principal component (PC2) is found along the straight line perpendicular to the previous principal component, and the second principal component is obtained, so repeatedly. In general, principal component analysis can be used when the total contribution rate of PC1 and PC2 is more than $85 \%$ [14].

PCA analysis can generally reflect the metabolic differences between the samples in each group and the variation between the samples in the group. The aggregation and dispersion of the samples can be observed from the PCA score diagram; the closer the sample distribution point, the closer the composition and concentration of the variables/molecules contained in these samples. On the contrary, the farther away the sample point, the greater the difference.

As shown in Fig. 3, the blue and green ellipse represents $\mathrm{CMB}$ and NB, respectively. The contribution rates of PC1 and PC2 were $99.93 \%$ and $0.03 \%$, respectively. The total contribution rate was 


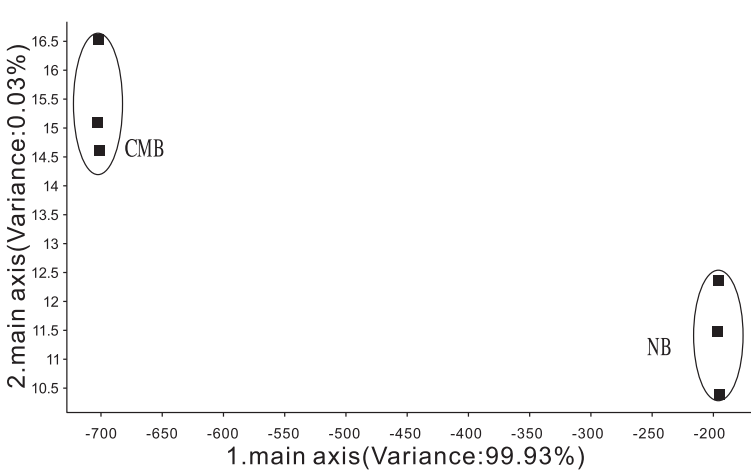

Fig. 3 PCA of volatile components in beer.

$99.96 \%$, which is more than $85 \%$, suggesting that both principal component could reflect the information of the original high dimensional matrix without any important information missing. The elliptical region in which the data acquisition points were located had a specific distribution area and did not overlap, which indicates that PCA can effectively distinguish the difference between the two kinds of beer. In terms of the distribution of ellipse, CMB was in the PC1 negative axis of $\mathrm{NB}$, indicating that the contribution rate of PC1 in CMB was smaller than that in NB and the contribution rate of PC2 was higher than that of NB. In terms of distance, CMB and NB were localized far away from each other, indicating that the odor components were significantly different. Therefore, GC-MS was needed to analyze volatile flavor components.

\section{Loading analysis}

Load analysis is used to judge the contribution rate of the sensor to volatile odor. The closer the response value of the sensor is to zero, the smaller its contribution to the overall fingerprint information and the smaller the recognition effect. In contrast, the greater the deviation from zero, the stronger the recognition ability. This e-nose consisted of 10 gas sensors and its main applications are presented in Table 1. The importance of volatile compounds could be differentiated by LA according to response value.

As shown in Fig. 4, the contribution rates of the first and second principal component were $99.65 \%$ and $0.26 \%$, respectively. Among them, W5S and W1C sensors had a great impact on the first principal component. Additionally, W2S sensor showed a large influence on the second principal component. It is inferred that electronic nose gave strong
Table 1 Performance of 10 sensors for PEN3 portable electronic nose.

\begin{tabular}{|c|c|c|c|}
\hline \multicolumn{2}{|c|}{ Sensor } & \multirow{2}{*}{$\begin{array}{l}\text { General description } \\
\text { Aromatic compounds }\end{array}$} & \multirow{2}{*}{$\begin{array}{c}\text { Reference } \\
\text { Toluene, } \\
10 \mathrm{ml} / \mathrm{m}^{3}\end{array}$} \\
\hline $\mathrm{R} 1$ & W1C & & \\
\hline $\mathrm{R} 2$ & W5S & $\begin{array}{l}\text { Very sensitive, broad range sensitivity, } \\
\text { react on nitrogen oxides }\end{array}$ & $\begin{array}{l}\mathrm{NO}_{2} \\
1 \mathrm{ml} / \mathrm{m}^{3}\end{array}$ \\
\hline R3 & W3C & $\begin{array}{l}\text { Ammonia, used as sensor for aromatic } \\
\text { compounds }\end{array}$ & $\begin{array}{l}\text { Benzene, } \\
10 \mathrm{ml} / \mathrm{m}^{3}\end{array}$ \\
\hline R4 & W6S & $\begin{array}{l}\text { Mainly hydrogen, selectively, (breath } \\
\text { gases) }\end{array}$ & $\begin{array}{c}\mathrm{H}_{2} \\
100 \mathrm{ml} / \mathrm{m}^{3}\end{array}$ \\
\hline R5 & W5C & $\begin{array}{l}\text { Aliphatic hydrocarbons, aromatic } \\
\text { compounds }\end{array}$ & $\begin{array}{r}\text { Propane, } \\
1 \mathrm{ml} / \mathrm{m}^{3}\end{array}$ \\
\hline R6 & W1s & Aromatic compounds & $\begin{array}{c}\mathrm{CH}_{4} \\
100 \mathrm{ml} / \mathrm{m}^{3}\end{array}$ \\
\hline R7 & W1W & Sulphur organic compounds & $\begin{array}{c}\mathrm{H}_{2} \mathrm{~S} \\
1 \mathrm{ml} / \mathrm{m}^{3}\end{array}$ \\
\hline R8 & W2S & Alcohol & $\begin{array}{c}\mathrm{NO}, \\
100 \mathrm{ml} / \mathrm{m}^{3}\end{array}$ \\
\hline R9 & W2W & $\begin{array}{l}\text { Aromatic compounds, sulphur organic } \\
\text { compounds }\end{array}$ & $\begin{array}{c}\mathrm{H}_{2} \mathrm{~S} \\
1 \mathrm{ml} / \mathrm{m}^{3}\end{array}$ \\
\hline R1C & W3S & Hydrocarbons & $\begin{array}{c}\mathrm{CH}_{4} \\
100 \mathrm{ml} / \mathrm{m}^{3}\end{array}$ \\
\hline
\end{tabular}

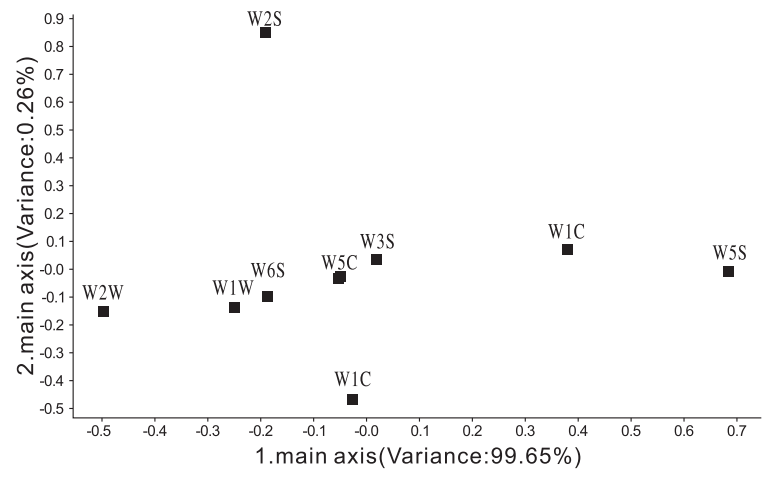

Fig. 4 Loading analysis of the volatile components in beer.

response to nitroxides, aromatic compounds and ethanol, implying that those are main volatile components.

Although ester content of CMB was less than that of NB but alcohol content was higher, the contribution rate of ester was more effective than alcohol counterpart. This result may be caused by the higher threshold value of alcohols than esters. Therefore, it is still a beer dominated by ester flavor.

\section{GC-MS}

As shown in Table 2 and Fig. 5, a total of 27 volatile compounds including 11 common volatile components were identified by SPME/GC-MS from CMB and NB. Among them, 19 volatile compounds in $\mathrm{CMB}$, accounting for $80.28 \%$ of total compounds, mainly included ethanol (23.24\%), isoamyl alcohol $(7.96 \%)$, isoamyl acetate (11.73\%), ethyl hex- 

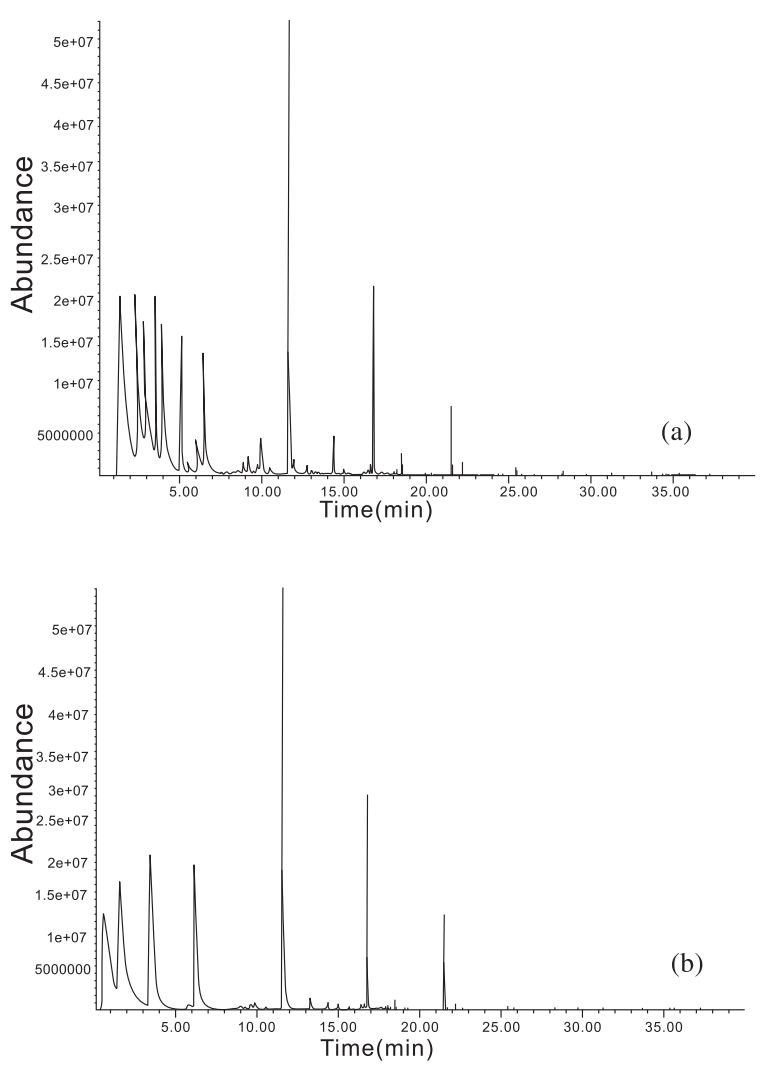

Fig. 5 GC-MS total ionic chromatogram of volatile compounds in (a) NB and (b) CMB.

anoate $(7.56 \%)$ and ethyl octanoate (12.47\%). Similarly, 19 volatile compounds in NB, accounting for $89.89 \%$ of total compounds, mainly included ethanol (21.3\%), isoamyl alcohol (9.36\%), isoamyl acetate $(19.86 \%)$, ethyl hexanoate $(12.91 \%)$ and ethyl octanoate (15.78\%). Main components were the same between CMB and NB and they produced some aroma such as fruity, flower and rose, suggesting both taste were similar. Meanwhile, compared with NB, ethyl caprylate was the ester compound with the highest amount instead of isoamyl acetate. And ethyl caprylate is the important flavor in rich fragrance white wine, contributing to aromatic fragrance [15]. Although acids in beer are difficult to volatilize and are not aroma component, they are main flavoring materials and could give debonaire taste $[16,17]$. Additionally, 8 kinds of substances such as butenate, 3-butanediol, methyl folate 1-caryophyllene were detected only in CMB, accounting for $15 \%$ of total volatile compounds, and establish CMB with unique taste.
Table 2 GC-MS analysis of volatile flavor compounds in beers.

\begin{tabular}{|c|c|c|c|c|}
\hline \multirow{2}{*}{ Class } & \multirow{2}{*}{ Identification } & \multicolumn{2}{|c|}{ Peak area $\%$} & \multirow{2}{*}{$\begin{array}{l}\text { Aroma } \\
\text { description }\end{array}$} \\
\hline & & CMB & NB & \\
\hline \multirow{3}{*}{ Acid } & Total & 1.12 & - & \\
\hline & Butenoic acid & 0.56 & - & - \\
\hline & Octanoic acid & 0.56 & - & $\begin{array}{l}\text { rancid, butter, } \\
\text { astringent }\end{array}$ \\
\hline \multirow{6}{*}{ Alcohol } & Total & 35.54 & 30.86 & \multirow{6}{*}{$\begin{array}{l}- \\
\text { fruity } \\
\text { rose }\end{array}$} \\
\hline & Ethanol & 23.24 & 21.30 & \\
\hline & Isoamyl alcohol & 7.96 & 9.36 & \\
\hline & Phenethyl alcohol & 0.21 & 0.16 & \\
\hline & 2-Butanediol & 4.13 & - & \\
\hline & Coriandrol & - & 0.08 & \\
\hline \multirow{19}{*}{ Ester } & Total & 43.48 & 58.96 & \multirow{7}{*}{$\begin{array}{l}\text { banana } \\
\text { fruity } \\
\text { pear, flower, } \\
\text { pineapple } \\
\text { flower, fruity, } \\
\text { soap } \\
\text { apple, soap } \\
\text { garnetberry, } \\
\text { pawpaw, fruit }\end{array}$} \\
\hline & Isoamyl acetate & 11.73 & 19.86 & \\
\hline & Ethyl hexanoate & 7.56 & 12.91 & \\
\hline & Ethyl caprylate & 12.47 & 15.78 & \\
\hline & Ethyl laurate & 0.89 & 1.68 & \\
\hline & Ethyl caprate & 3.57 & 4.33 & \\
\hline & Ethyl pelargonate & 0.63 & 0.16 & \\
\hline & Methyl folate & 0.78 & - & \\
\hline & Ethyl 4-decenoic acid & 0.65 & - & - \\
\hline & N-butyl octanoate & 4.59 & - & - \\
\hline & Ethyl palmitate & 0.33 & - & wax, butter \\
\hline & Phenylethyl acetate & - & 2.50 & honey, apple \\
\hline & Cognac oil & - & 0.56 & jackfruit \\
\hline & $\begin{array}{l}\text { Trans-4-decenoic } \\
\text { acid ethyl ester }\end{array}$ & - & 0.13 & - \\
\hline & Ethyl 9-decenoate & - & 0.16 & - \\
\hline & $\begin{array}{l}\text { 3-Methyl butyl } \\
\text { sebacate }\end{array}$ & - & 0.17 & - \\
\hline & Methyl arachidonate & - & 0.18 & - \\
\hline & $\begin{array}{l}\text { Octanoic acid } \\
\text { 3-methyl butyl ester }\end{array}$ & 0.30 & 0.58 & fruity \\
\hline & Ethyl myristate & - & 0.03 & - \\
\hline \multirow{3}{*}{ Terpene } & Total & 0.14 & 0.06 & \multirow{3}{*}{$\begin{array}{l}\text { clove } \\
\text { slightly clove }\end{array}$} \\
\hline & Caryophyllene & 0.09 & 0.06 & \\
\hline & 1-Caryophyllene & 0.05 & - & \\
\hline
\end{tabular}

\section{DISCUSSION}

Nowadays, the main production process of health benefit beer uses the additive method. For example, the active component extract in Chinese medicine herbs can be added directly in the saccharification process of beer production or in the brewing process or after fermentation [18]. In the present study, CME was added in the brewing process and then the volatile flavor compounds in $\mathrm{CMB}$ were analyzed by SPME/GC-MS and electronic nose compared with $\mathrm{NB}$ as control. Obtained results showed that 8 kinds of compounds were detected only in $\mathrm{CMB}$, which is probably attributed to microorganism fermentation. The microorganism fermentation theory in Chinese herbal medicine suggests that microorganism could secrete some enzymes, break the cell structure and increase the content of bioactive substances [19]. Meanwhile, some macromolecular even toxic substances could be degraded to simple compounds 
that could be absorbed directly or transformed to new compounds [20]. With respect to the other 8 compounds detected only in NB, combined with conclusion of electronic nose analysis, exactly ester content of CMB was less than that of NB while alcohol content was higher. The reason may be that CME possessing antioxidant activity promoted the production of reducing agents such as glutathione in yeast cells under oxidative stress [21] and thus inhibited formation of esteryl coenzyme A in fatty acid oxidation. It is known that condensation reaction of alcohols with esteryl coenzyme A in yeast is the main pattern of ester production [22].

Furthermore, it is reported that extracts of herbal medicines possess antimicrobial activity [2326]. Thus, it may influence fermentation by inhibiting the metabolism of microorganisms such as yeast. However, whether antioxidant or antimicrobial activity of CME influenced the formation of flavor of $\mathrm{CMB}$, further study is needed to investigate the mechanism of changes of flavor compounds.

Overall, addition of CME changed the composition of volatile components, but did not reduce their types. It introduces $\mathrm{CMB}$ with unique taste and health benefit.

Acknowledgements: The authors would like to thank the Shandong Province Modern Agricultural Industry Technology System (SDAIT-07-07) and Shandong Province Science and Technology Development Planning Project (2014GNC113007) of China for supporting this research.

\section{REFERENCES}

1. Liu XL, Narasimha-kumar K, Li Y, Deng YP, Zheng XQ (2017) Biochemical characterization of a novel fibrinolytic enzyme from Cordyceps militaris. Int $J$ Biol Macrommol 94, 793-801.

2. Lou HW, Ye ZW, Yu YH, Lin JF, Guo LQ, Chen BX, Tang HB, Wei T, et al (2019) The efficient genetic transformation of Cordyceps militaris by using mononuclear protoplasts. Sci Hortic 243, 307-313.

3. Cheng XH, Gai YP, Sun HY, Bai XF, Zhang QS (2010) Zinc tolerance and accumulation characteristics of Cordyceps militaris. Acta Ecol Sin 30, 1449-1455.

4. Pang WQ, Jiang X, Guo DJ (2017) Analysis of volatile components in wild blueberry juice and the fermented blueberry wine. China Brew 36, 180-185.

5. Yang H, Liu YN, Guo DJ (2017) GC-MS analysis of aromatic composition of Vaccinium vitis-idaea wine fermented by 3 species of yeast strains. J Chin Inst Food Sci Technol 17, 263-273.

6. Yin XJ, Chen G, Jian SP, Zheng SD, Huang LS, Shi JX (2018) Effects of diammonium phosphate on the fermentation performance and volatiles composition of jujube wine. Food Sci 39, 132-137.
7. Tian TT, Yang H, Yang F, Li BW, Sun JY, Wu DH, Lu J (2018) Optimization of fermentation conditions and comparison of flavor compounds for three fermented greengage wines. LWT-Food Sci Technol 89, 542-550.

8. Yu G, Wang L, Hu XL, Sun YN, Zhang X, Li M, Li WX (2018) Optimization of extraction process of cordycepin and adenosine from Cordyceps militaris solid fermentation products by response surface methodology. Food Sci 39, 270-275.

9. Zhu Z, Chen YL, Shi GQ (2017) Selenium delays tomato fruit ripening by inhibiting ethylene biosynthesis and enhancing the antioxidant defense system. Food Chem 219, 179-184.

10. Sánchez AH, López-López A, Cortés-Delgado A, Beato VM, Medina E, de Castro A, Montaño A (2018) Effect of post-fermentation and packing stages on the volatile composition of Spanish-style green table olives. Food Chem 239, 343-353.

11. Zhou N, Yang XH, Xie WC, Mo XY, Gao Q (2016) Analysis of nutrition and valitile flavor of guava fruit (Psidium guajava L.). Food Machinery 32, 37-40. [in Chinese]

12. Li M, Yang R, Zhang H, Wang S, Chen D, Lin S (2019) Development of a flavor fingerprint by HS-GC-IMS with PCA for volatile compounds of Tricholoma matsutake Singer. Food Chem 290, 32-39.

13. Zou GY (2019) Quality detection of xinyang maojian tea based on eletronic nose and electronic tongue. MSc thesis, Henan Agricultural Univ, China.

14. Su KZ, Luo YH, Li XC, Li GL (2020) Effect of frying time on sensory evaluation and electronic nose analysis of Lipu taro. Food Machinery 4, 1-6. [in Chinese]

15. Li ZB, Li L (2013) An important component in Luzhou flavor liquor-analysis of ethyl caprylate content and its contribution. Niang Chiu 2013(3), 33-36. [in Chinese]

16. Xiang Y, Li Q, Gu GX (2007) Study on composition of organic acids in domestic beer for comprehensive evaluation. Food Sci 28, 266-270. [in Chinese]

17. Wang ZJ (2006) Organic acids in beer and its effects on beer flavor. Liquor Making Sci Technol 2006(9), 121-122. [in Chinese]

18. Wang LL, Liu SY (2019) Development status of craft beer. Food Eng 3, 1-3.

19. Jeong SY, Velmurugan P, Lim JM, Oh BT, Jeong DY (2018) Photobiological (LED light)-mediated fermentation of blueberry (Vaccinium corymbosum L.) fruit with probiotic bacteria to yield bioactive compounds. LWT-Food Sci Technol 93, 158-166.

20. Chen T, Xiong S, Wang M, Wu Q, Wei H (2012) Effects of traditional Chinese medicines on intestinal bacteria: a review. Indian J Tradit Know 11, 401-407.

21. Zheng LX, Qi B, Sun J, Wang LM (2017) Effects of exogenous oxidation stress on glutathione synthesis in Saccharomyces cerevisiae mutant Y518. Food Machinery 33, 15-19. [in Chinese] 
22. Rojas V, Gil J, Manzanares P, Gavara R, Piñaga F, Flors A (2002) Measurement of alcohol acetyltransferase and ester hydrolase activities in yeast extracts. Enzyme Microb Tech 30, 224-230.

23. Mulaudzi RB, Tshikalange TE, Olowoyo JO, Amoo SO, Du Plooy CP (2017) Antimicrobial activity, cytotoxicity evaluation and heavy metal content of five commonly used South African herbal mixtures. S Afr $J$ Bot 112, 314-318.

24. Mazzei R, Leonti M, Spadafora S, Patitucci A, Tagarelli G (2020) A review of the antimicrobial potential of herbal drugs used in popular Italian medicine (1850s-1950s) to treat bacterial skin diseases. $J$ Ethnopharmacol 250, ID 112443.

25. Zhou S, Dong J, Liu Y, Yang Q, Xu N, Yang Y, Gu Z, Ai X (2020) Anthelmintic efficacy of 35 herbal medicines against a monogenean parasite, Gyrodactylus kobayashii, infecting goldfish (Carassius auratus). Aquaculture 521, ID 734992.

26. Jarriyawattanachaikul W, Chaveerach P, Chokesajjawatee N (2016) Antimicrobial activity of Thaiherbal plants against food-borne pathogens E. Coli, S. Aureus and C. Jejuni. Agric Agric Sci Procedia 11, 20-24. 